\title{
Experimental Study on the Damage of Artificial Fracture Permeability in Coal during the Flow Back of Guar-Based Fracturing Fluid
}

\author{
Shenggui Liu $\mathbb{D},{ }^{1}$ Jinkuang Huang $\mathbb{D},{ }^{1}$ Songlei Tang $\mathbb{D},{ }^{1}$ Shixiong Shi, ${ }^{1}$ Xuan $W u,{ }^{1}$ \\ and $\mathrm{Xin} \mathrm{Liu}^{2}$ \\ ${ }^{1}$ School of Mechanics and Civil Engineering, China University of Mining and Technology (Beijing), Beijing 100083, China \\ ${ }^{2}$ Jining No.3 Coal Mine, Yanzhou Mining Group Co. Ltd, Jining, Shandong 272000, China \\ Correspondence should be addressed to Jinkuang Huang; cumtb_huangjk@126.com
}

Received 5 January 2020; Accepted 15 February 2020; Published 18 April 2020

Guest Editor: Hui Pu

Copyright (C) 2020 Shenggui Liu et al. This is an open access article distributed under the Creative Commons Attribution License, which permits unrestricted use, distribution, and reproduction in any medium, provided the original work is properly cited.

\begin{abstract}
After the completion of fracturing operation in coalbed methane (CBM), the fracturing fluid needs to flow back to the ground in time to reduce the damage to the coal reservoir. The damage of guar-based fracturing fluid to the coal reservoir has an adverse effect on the fracturing stimulation. A series of flow experiments were carried out with the unconventional natural gas reservoir damage evaluation equipment. This paper investigates the evolution of fracture permeability in coal samples during the process of hydroxypropyl guar (HPG) fracturing fluid flow back. The experimental results show that the fracturing fluid concentration, proppant type, proppant particle size, and proppant concentration all affect fracture permeability. The high concentration of fracturing fluid caused irreversible damage to fracture permeability of coal samples. With the increase of fracturing fluid concentration, the permeability damage rate increased from $65.31 \%$ to $84.57 \%$, and the damage degree was strong. KCL brine flushing can only decrease the damage rate of coal sample fracture permeability within a certain range. The proppant embedment and the generation of pulverized coal exacerbated the damage of fracture permeability. The research results can be beneficial for optimizing the type and performance of fracturing fluid for hydraulic fracturing in CBM reservoir.
\end{abstract}

\section{Introduction}

Coalbed methane (CBM) is an unconventional natural gas resource. China is rich in CBM resources and has great development potential [1]. However, due to the late start of unconventional gas development in China, complicated geological conditions and low single well production, further exploration and research on exploration and development technologies are needed [2]. CBM exploration and development tests over the years have shown that China's CBM reservoir have the geological characteristics of low permeability, low pressure, and low gas saturation, as well as strong adsorption [3]. Hydraulic fracturing is the most effective technical means in the process of CBM stimulation. CBM wells need to undergo hydraulic fracturing to enter the stage of drainage and production. The quality of hydraulic fracturing directly affects the level of gas production in the later stage $[4,5]$.

Reservoir damage is an inevitable problem in CBM development. Fracturing fluid damage to hydraulic fracture is an important part in the field of reservoir damage [6]. Hydraulic fracturing is generally required for low permeability CBM reservoir to obtain economic gas production. The fracturing process mainly includes forming fractures by injecting pad fluid, then injecting sand-carrying fluid, and finally injecting displacement fluid. The fracturing fluid should meet the characteristics of little filtration, strong sand-carrying capacity, low friction, low residue, and easy flow back [7]. During the fracturing process, a large amount of liquid needs to be pumped at the bottom of the well to rupture the formation to produce fractures, and a large amount of fracturing fluid 
will enter the coal reservoir. At present, the commonly used CBM fracturing fluids include active water fracturing fluid, cross-linked gel fracturing fluid, clean fracturing fluid, and foam fracturing fluid [8]. Hydroxypropyl guar (HPG) is a type of cross-linked gel fracturing fluid, which is commonly used in hydraulic fracturing [9].

The permeability of CBM reservoir is low, generally less than $1 \mathrm{mD}$, and Young's modulus is low; fracturing fluid is easy to cause damage to the coal reservoir $[10,11]$. High viscosity of CBM fracturing fluid is necessary to ensure width generation and proppant carrying capabilities. Fracturing fluid must be capable of completely gel breaking in a short time and flow back as soon as possible to reduce damage to coal reservoir [12] On the one hand, compared with the active water fracturing fluid, the cross-linked gel fracturing fluid has the advantages of strong sand-carrying capacity, low filtration, and strong width generation capacity. On the other hand, when the coal seam temperature is low, the cross-linked gel fracturing fluid has problems such as difficulty in gel breaking, incomplete gel breaking, and residue adsorption damage $[10,13]$. It will cause the difficulty of fracturing fluid flow back in the coal seam, which is serious damage to the coal seam. Solid particles (water insoluble and residue) in the fracturing fluid can invade the coal reservoir and stick to the proppant pores [14]. The decrease of porosity resulted in the decrease of permeability of the supporting fracture. In addition, due to the adsorption of fracturing fluid, the matrix expands and the pores decrease, which reduces the conductivity of fractures [15]. Therefore, the fracturing flow back process is an important factor that affects the fracturing effect.

Reducing the damage of fracturing fluid to the permeability of CBM reservoir is an important measure to improve the effect of hydraulic fracturing. Many scholars have conducted significant research into the damage of fracturing fluid to permeability $[7,16,17]$. By comparing the influence of clean fracturing fluid and water on coal seam permeability, some scholars have obtained that clean fracturing fluid can effectively decrease the surface fluid tension of coal body pores and increase the gas migration channel. As a result, the coal seam permeability is improved, which is conducive to the drainage of CBM [18]. Some studies have been carried out on the microscopic mechanism of fracturing fluid damage in the process of fracturing. The cause of insoluble substances in the process of gel breaking was the difficulty in the complete degradation of guar molecules and the reduced solubility of guar gum [19]. In order to study the effect of fracturing fluid treatment on the pore structure of coal in different systems, isothermal adsorption experiments of coal samples before and after fracturing fluid treatment were carried out. The degree of impact of the fracturing fluid system on the coal samples pore structure, from large to small, is guar gum fracturing fluid, active water fracturing fluid, and clean fracturing fluid. Changes in the pore structure of coal will change the methane gas adsorption capacity [20]. Some researchers found that both guar gum fracturing fluid and slickwater can pose a significant permeability decrease in coal $[17,21]$. Highconcentration guar gum fracturing fluid will cause serious damage to coal permeability, and the permeability cannot be recovered significantly after water washing [22, 23]. Some significant research showed that the proppant concentration influences the permeability reduction result from the fracturing fluid [24].

In recent years, investigation has been carried out to the permeability damage caused by the interaction between fracturing fluid and coal reservoir during hydraulic fracturing [8]. In order to realize the desorption and migration of $\mathrm{CBM}$, the pressure of the coal reservoir should be reduced to below the critical desorption pressure through drainage and depressurization [25]. Under the condition of the proppant in the coal reservoir, the research on the damage of fracturing fluid to support fracture conductivity is limited. Reservoir permeability damage needs a further research, including the flushing of fracturing fluid residue during drainage and the evolution of permeability during flushing. Despite of the huge CBM and shale gas reserves in the unconventional reservoirs, how to improve recovery factors from unconventional oil and gas reservoirs is an inevitable problem. Therefore, it is necessary to conduct research on unconventional oil and gas reservoirs [26]. In order to improve the effect of hydraulic fracturing, primary structural coal was selected to study the damage to coal permeability caused by fracturing fluid. This paper focused on the retention damage of HPG fracturing fluid in the proppant pack and studied the effects of different experimental parameters on the retention damage of fracturing fluid. The purpose of this experiment is to study the causes for the significant permeability reduction of the coal reservoir after fracturing fluid flow back.

\section{Experiment Description}

2.1. Experimental Apparatus and Coal Samples. With the American Petroleum Institute (API) standard, this paper studies the damage of CBM fracturing fluid to reservoir permeability and evaluates the permeability damage rate of coal sample. The coal sample used in the experiment is bituminous coal, which comes from the No. 3 coal seam of Shandong. The coal samples used in the experiment were drilled from primary structural coal without macroscopic cracks. After cutting and polishing, the coal sample is processed into a cylinder $(50 \times 100 \mathrm{~mm})$ with a diameter of $50 \mathrm{~mm}$ and a length of $100 \mathrm{~mm}$, with the length to diameter ratio of $2: 1$ to eliminate the end effect. Figure 1 is the coal sample used in the experiment. The coal sample is cut in half along the axial direction of the core with the saw machine to produce a smooth surface. The cutting surface of the coal is polished to remove the tiny saw teeth to form a smooth artificial fracture. The proppant used in this study are ceramic proppant and quartz sand proppant. The particle size range is 20-40 mesh, 40-70 mesh, and 70-100 mesh.

This experiment was conducted with the unconventional natural gas reservoir damage evaluation equipment. The equipment mainly includes the core holder, confining pressure control device, constant-flux pump, pressure sensor, electronic balance, and intermediate container. The equipment injection flow setting range is $0.1-9.99 \mathrm{~mL} / \mathrm{min}$, and the pressure setting range is $0.1-50 \mathrm{MPa}$. Figure 2 shows the unconventional gas reservoir damage assessment equipment used in the experiment. The computer connected to the device can record the 


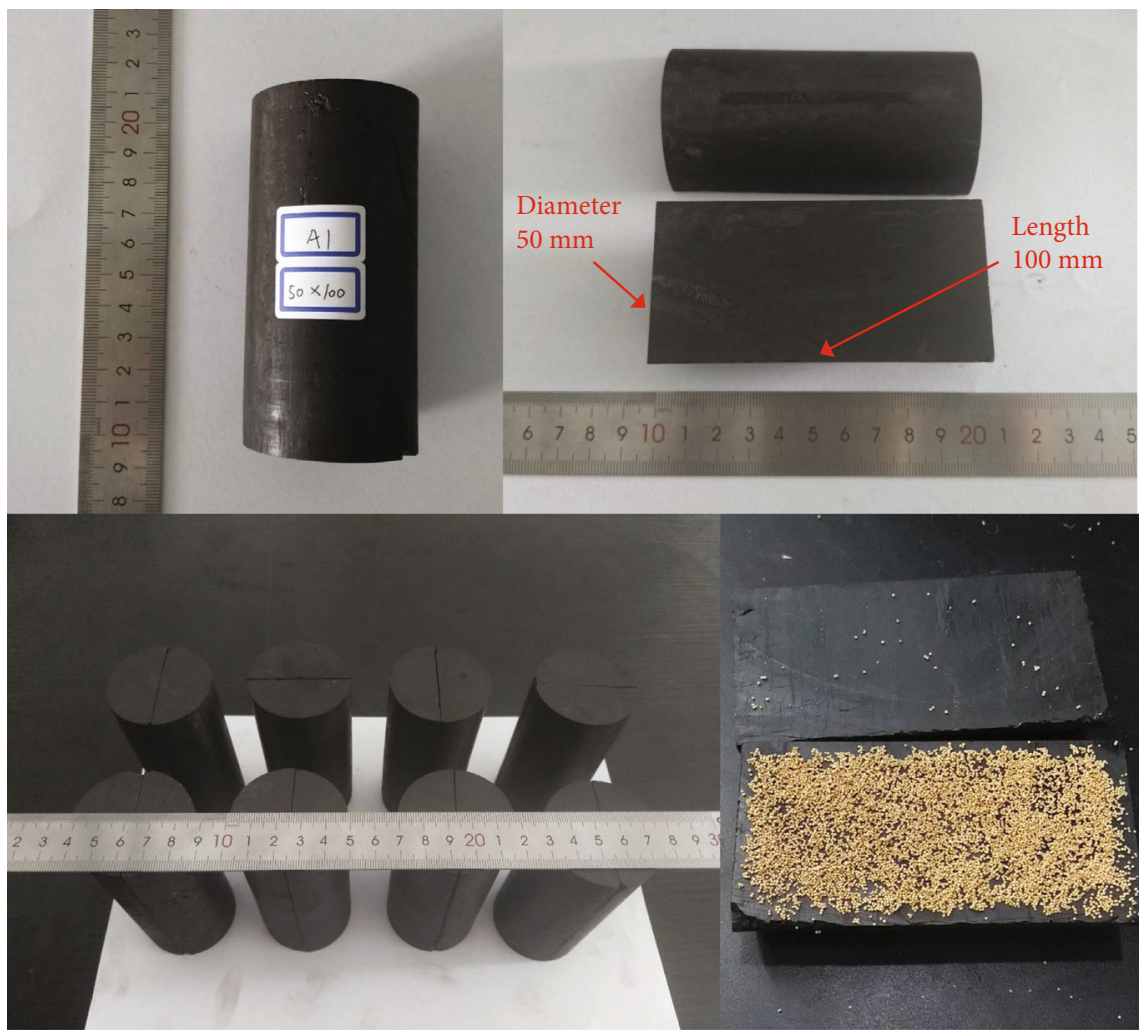

FIgURE 1: Pictures of coal samples used in the experiment.

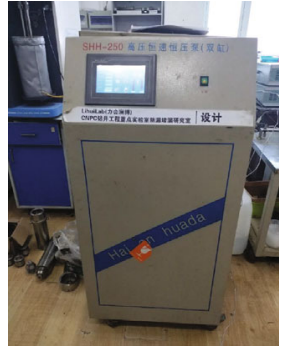

(a)

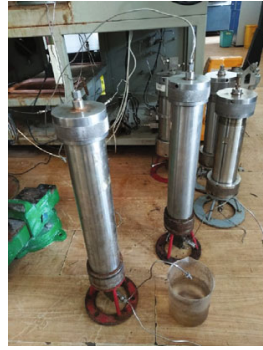

(b)

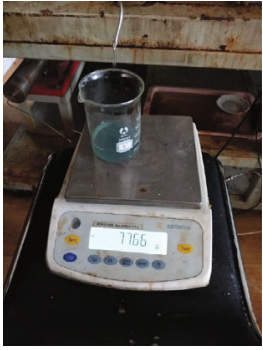

(c)

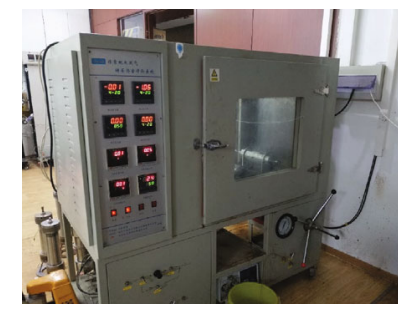

(d)

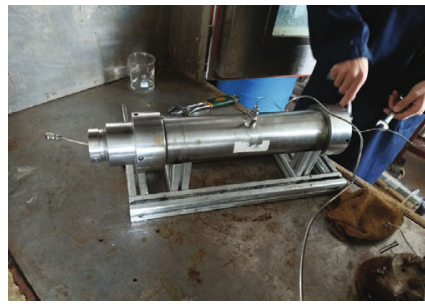

(e)

Figure 2: Unconventional natural gas reservoir damage evaluation equipment. (a) Constant-flux pump. (b) Intermediate container. (c) Electronic balance. (d) Confining pressure control device. (e) The core holder.

displacement pressure and outlet flow of the measured core at a fixed time, and the electronic balance can record the quality difference at a fixed time. The data recording system will automatically calculate the permeability of the coal sample.

2.2. Fracturing Fluid. In the industry of CBM, hydraulic fracturing technology has been widely used and fracturing fluid is an important part of fracturing operation. Research on the damage of fracturing fluid to coal reservoir has become the focus of fracturing operation. After the large molecules polymer in the fracturing fluid enters the formation, a considerable part cannot be completely broken. The residual polymer will damage the permeability of the coal reservoir and greatly reduce the effect of fracturing operation. The HPG fracturing 
TABLE 1: The main components of each group of fracturing fluids.

\begin{tabular}{lllll}
\hline \multirow{2}{*}{ Group no. } & Thickener & Cross-linker & Antiswelling agent & Breaker \\
\hline 1 & Hydroxypropyl guar (0.1\%) & & \\
2 & Hydroxypropyl guar (0.2\%) & The organic boron $(0.4 \%)$ & The KCl (1.5\%) & The ammonium persulfate (0.04\%) \\
3 & Hydroxypropyl guar (0.3\%) & & \\
4 & Hydroxypropyl guar (0.4\%) & & \\
\hline
\end{tabular}

fluid system has little environmental pollution, which is the research and application direction of fracturing fluid at present [27]. In the northern San Juan Basin and the Black Warrior Basin of the United States, organic borate crosslinked HPG is generally used as the fracturing fluid [28]. With stable properties and relatively low price, HPG is widely used in the modification of guar gum. By comparing the permeability of coal sample measured before and after the injection of fracturing breaking fluid, the damage of fracturing fluid to artificial fracture permeability was evaluated. The guar-based fracturing fluid is mainly composed of thickener, cross-linker, gel breaker, antiswelling agent, drainage aid, and so on [29]. The main ingredients are as follows: thickener (HPG, effective content 95\%), cross-linker (organic boron cross-linker, effective content $30 \%$ ), gel breaker (ammonium persulfate, effective content 98\%), and antiswelling agent (KCL). The main components of each group of fracturing fluids are shown in Table 1.

HPG fracturing fluid with different concentrations $(0.1 \%$, $0.2 \%, 0.3 \%$, and $0.4 \%$ ) was prepared according to the petroleum and natural gas industry standard SY/T 5107-2005 "Methods for Performance Evaluation of Water-Based Fracturing Fluids" [30]. After preparing different concentrations of HPG solution, a $1.5 \%$ antiswelling agent (KCL solution) was added. Finally, a $0.4 \%$ organic boron cross-linking agent was added to conduct cross-linking while stirring. The strong oxidant ammonium persulfate is used to break the gel. The HPG fracturing fluid is easy to break with ammonium persulfate. The viscosity of fracturing fluid after breaking is less than $10 \mathrm{mPa}-\mathrm{s}$, and it is easy to flow back after KCL brine flushing.

2.3. Experimental Methods. The proppant used in this experiment are ceramic proppant and quartz sand proppant with different particle sizes. The proppant meets the hydraulic fracturing proppant performance indicators and industry standards. The appropriate amount of ceramic proppant was weighed and placed between the fracture of the prepared coal sample with different concentrations. Proppant uniform placement was ensured to avoid large gaps affecting the accuracy of the experiment. The pressure and flow of the advection pump were maintained in a stable and reasonable range. First, the initial permeability of the supporting fracture was measured with $1 \%$ KCL brine, and the gel breaking fluid of different concentrations was injected to record the permeability changes. Then the reverse $1 \%$ KCL brine was added to simulate the process of fracturing fluid flow back in hydraulic fracturing. The permeability was measured in the same way, and the recovery of permeability was observed after brine flushing. A microscope was utilized to observe the adhesion of the gel breaking fluid residue on the proppant surface and the blockage of the pores after the experiment.

\subsection{Experimental Steps}

2.4.1. Experimental Preparation. The ceramic proppant and quartz sand proppant of different particle sizes were prepared, and the proppant was placed in a coal sample fracture. The HPG solution was configured with different concentrations, the experimental equipment was debugged, and the permeability damage experiment of the coal sample was conducted.

2.4.2. Initial Permeability Test. The coal sample was loaded into the core holder, $1 \% \mathrm{KCL}$ brine was placed in a $1000 \mathrm{~mL}$ intermediate container, one end of the intermediate container was connected to the constant-flux pump, and the other end was connected to the inlet end of the core holder. The unconventional natural gas reservoir damage evaluation equipment was opened, different confining pressure values and injection flow rate were set, and the initial permeability of coal sample under different experimental conditions was tested. When the inlet pressure of the core holder stabilizes, the experiment was stopped and the initial permeability value was recorded.

2.4.3. Inject HPG Fracturing Fluid. After the initial permeability test is completed, the intermediate container containing the HPG solution is replaced. The intermediate container is connected with the core holder and the constant-flux pump, and a certain amount of HPG solution is pumped into the ceramic proppant pack.

2.4.4. KCL Brine Flushing. The intermediate container with $\mathrm{KCL}$ brine was replaced. One end of the intermediate container was connected to the constant-flux pump and the other end to the outlet of the core holder. By changing the direction of fluid pumping, the flow back of fracturing fluid during the fracturing operation was simulated, and the permeability recovery was observed by controlling the injection flow rate and flow back time.

2.4.5. KCL Brine Flushing Permeability Test. In the same way as the initial permeability test, the permeability was recorded after KCL brine flushing.

2.4.6. Permeability Damage Rate Calculation. The above steps were repeated to determine the permeability data of different concentrations of HPG solution, different proppant particle sizes, different proppant types, and different proppant concentrations. The Darcy formula was used to 


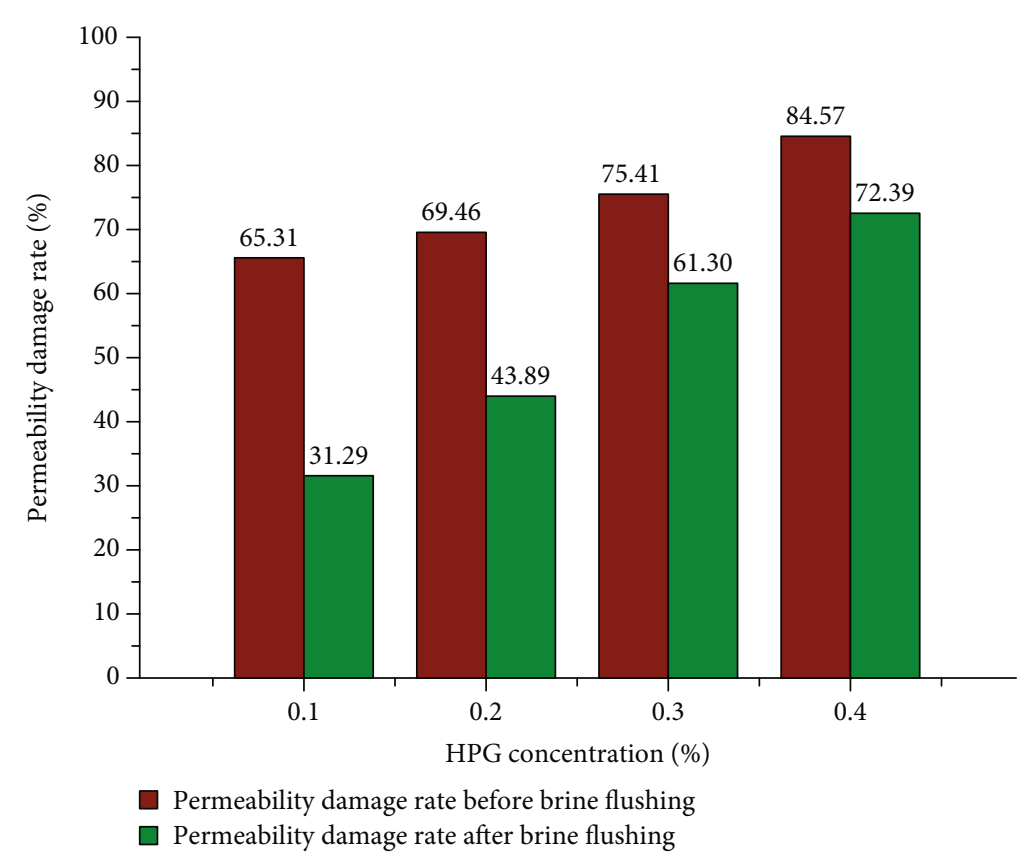

FIGURE 3: Influence of fracturing fluid concentration on coal sample permeability.

calculate the permeability of the HPG solution before and after damage. The permeability damage rate was calculated.

\section{Experimental Results}

3.1. Data Processing. In this paper, the method of measuring permeability is the steady-state method to record the pressure difference between the two ends of the coal sample at a constant flow rate [31]. The permeability of coal sample fractures is calculated using Darcy's law. The formula is as follows [32]:

$$
k=\frac{Q \mu L}{A \Delta P}
$$

where $k$ is liquid permeability, $\mathrm{mD}$; $Q$ is liquid volume flow rate, $\mathrm{mL} / \mathrm{min} ; \mu$ is fluid viscosity, $\mathrm{mPa}$-s; $L$ is the length of the coal sample, $\mathrm{cm} ; A$ is the cross-sectional area of the coal sample proppant pack, $\mathrm{cm}^{2}$; and $\Delta P$ is the pressure difference between the upper port and the lower port of the coal sample, MPa.

To better characterize the damage degree of coal sample fracture permeability caused by the HPG fracturing fluid, the recovery of permeability was quantitatively analyzed. We use the concept of permeability damage to describe the permeability changes before and after the HPG fracturing fluid damage. The higher the permeability damage rate, the more serious the permeability damage degree is. The calculation formula of permeability damage rate is as follows [33]:

$$
\eta=\frac{k_{1}-k_{2}}{k_{1}} \times 100 \%
$$

where $\eta$ is the permeability damage rate, dimensionless; $k_{1}$ is the permeability before the damage, $\mathrm{mD}$; and $k_{2}$ is the permeability after the damage, $\mathrm{mD}$.

\subsection{Factors Influencing Permeability Damage Rate}

3.2.1. Fracturing Fluid Concentration. HPG solutions were prepared with different concentrations $(0.1 \%, 0.2 \%, 0.3 \%$, and $0.4 \%$ ), ceramic proppant of 20-40 mesh, confining pressure of $20 \mathrm{MPa}$, and proppant concentration of $2 \mathrm{~kg} / \mathrm{m}^{2}$ $(10 \mathrm{~g})$; the fracturing fluid permeability damage test was performed. The damage rate of permeability was recorded at different fracturing fluid concentrations. The experimental data are shown in Figure 3.

It can be obtained from Figure 3 that with the increase of the fracturing fluid concentration, the permeability damage rate increased from $65.31 \%$ to $84.57 \%$, and the damage degree changed from moderate to strong. After flushing with KCL brine, the permeability of the coal samples using lowconcentration HPG solution $(0.1 \%, 0.2 \%)$ recovered well, and the permeability damage rates decreased to $31.29 \%$ and $43.89 \%$, respectively. In contrast, the permeability damage rate of coal samples using high-concentration HPG solution $(0.3 \%, 0.4 \%)$ has a slight decrease after brine flushing, but the damage rate was still above $60 \%$, which is a strong damage degree. The experimental results show that the concentration of fracturing fluid directly determines the recovery of permeability. When the concentration of HPG fracturing fluid is greater than $0.3 \%$, the damage to permeability is great and it is difficult to recover.

3.2.2. Proppant Type. Under the conditions of proppant concentration of $2 \mathrm{~kg} / \mathrm{m}^{2}(10 \mathrm{~g})$, a confining pressure of $20 \mathrm{MPa}$ and a fracturing fluid concentration of $0.2 \%$, the ceramic proppant and quartz sand proppant with different particle 


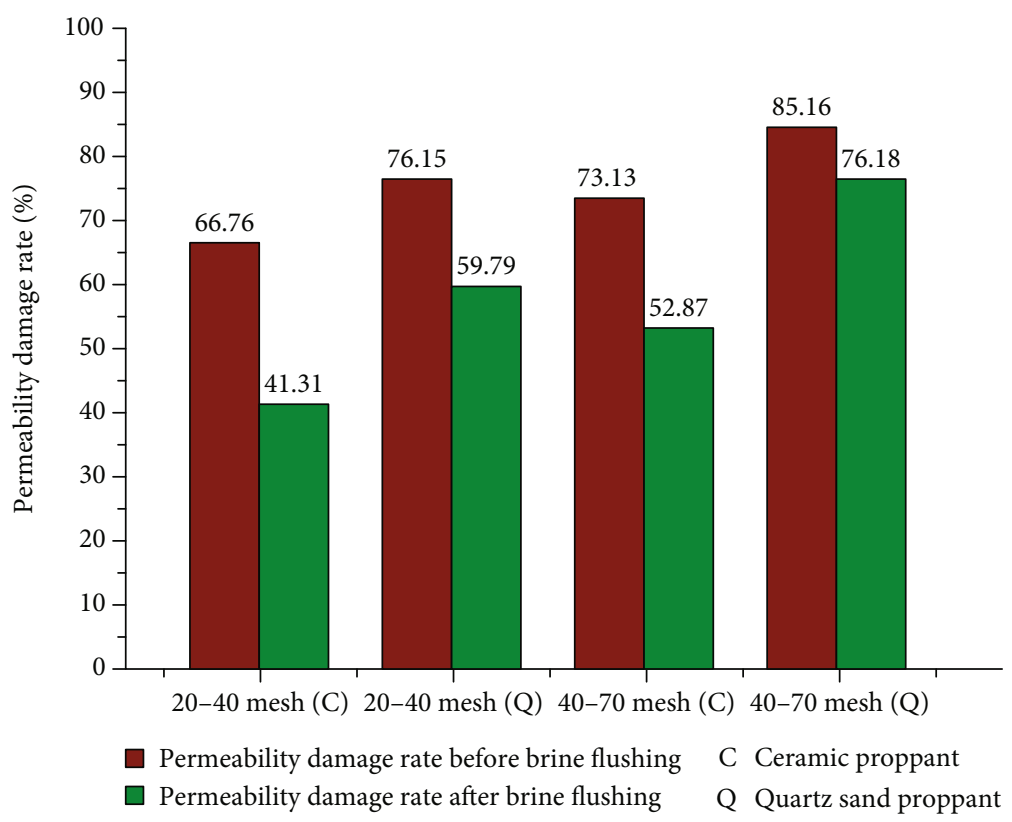

FIGURE 4: Influence of different proppant types on coal sample permeability damage rate.

sizes (20-40 mesh, 40-70 mesh) were used to conduct a coal sample permeability damage experiment. The relevant experimental data are shown in Figure 4.

It can be obtained from Figure 4 that when the particle size is 20-40 mesh and 40-70 mesh, the permeability damage rate of the quartz sand proppant is higher than that of the ceramic proppant. After KCL brine flushing, the permeability of coal sample with ceramic proppant recovers well, and the permeability damage rate permeability decreases significantly, and the damage rate is less than $60 \%$. When quartz sand proppant is used, the damage of permeability is significantly greater than that of the ceramic proppant group before and after KCL brine flushing, and the improvement of permeability damage by brine flushing is limited. When the proppant is quartz sand of $40-70$ mesh, the permeability damage rate is still as high as $76.18 \%$ after KCL brine flushing. The experimental results demonstrate that the larger the proppant particle size is, the lower the permeability damage rate is. Both ceramic proppant and quartz sand proppant are consistent with this rule. This is mainly because the sphericity of the ceramic proppant is greater than that of the quartz sand proppant. Under the same conditions, the porosity of the ceramic proppant pack is higher and the brine flushing effect is better.

3.2.3. Brine Flushing. The ceramic proppant with different particle sizes are selected for the permeability damage test. The large particle size is 20-40 mesh, the medium particle size is 40-70 mesh, and the small particle size is 70-100 mesh. The concentration of HPG is $0.3 \%$, and the confining pressure is set to $20 \mathrm{MPa}$. The experiment is performed according to API, using 1\% KCL brine as the fluid medium, and the proppant concentration is $2 \mathrm{~kg} / \mathrm{m}^{2}$ ( $10 \mathrm{~g}$ ). Taking the permeability damage rate as the ordinate and the volume of injected coal sample liquid (including injected fracturing fluid and KCL brine) as the abscissa, the permeability damage rate change curves under different flow rates of brine flushing are obtained. The change curve of the permeability damage rate is shown in Figure 5.

The experimental results demonstrate that after the injection of HPG fracturing fluid, the permeability of the three groups of the coal samples has been seriously damaged. The smaller the proppant particle size has the higher the permeability damage rate, and the ceramic proppant of 70-100 mesh has the most serious damage, with a damage rate of over $85 \%$. By injecting brine at different flow rates to flush the fracture, the permeability damage of the three coal samples gradually decreased. When the flow rate is $3 \mathrm{~mL} / \mathrm{min}$, the flushing time is $30 \mathrm{~min}, 90 \mathrm{~mL}$ of KCL brine is injected, and the permeability slightly recovers. Increasing the brine flow rate to $5 \mathrm{~mL} / \mathrm{min}$, the ceramic proppant permeability of the 20-40 mesh and 40-70 mesh has been greatly recovered. Therefore, the permeability damage rate is significantly reduced. However, the ceramic proppant of 70-100 mesh permeability damage has slightly changed. The brine flow rates are changed to $7 \mathrm{~mL} / \mathrm{min}$ and $9 \mathrm{~mL} / \mathrm{min}$, respectively, and the flushing time is both $30 \mathrm{~min}$. The proppant permeability of different particle sizes recover significantly, and the permeability damage rate is reduced from $75 \%$ to $55 \%$ at 20-40 mesh. The damage rate of 40-70 mesh and 70-100 mesh ceramic proppant permeability decreased by $15 \%$ and $10 \%$, respectively. The brine flow rate is readjusted to $1 \mathrm{~mL} / \mathrm{min}$, and the coal samples permeability of three groups remained unchanged.

3.2.4. Influence of Various Proppant Concentration. The concentration of one layer proppant is $1 \mathrm{~kg} / \mathrm{m}^{2}$ (ceramic proppant $5 \mathrm{~g}$ ), the concentration of two layers proppant is $2 \mathrm{~kg} / \mathrm{m}^{2}$ (ceramic proppant $10 \mathrm{~g}$ ), and the concentration of three layers proppant is $3 \mathrm{~kg} / \mathrm{m}^{2}$ (ceramic proppant $15 \mathrm{~g}$ ). The ceramic proppant of $20-40$ mesh is used as proppant, and the concentration of HPG is $0.2 \%$. The fracturing fluid 


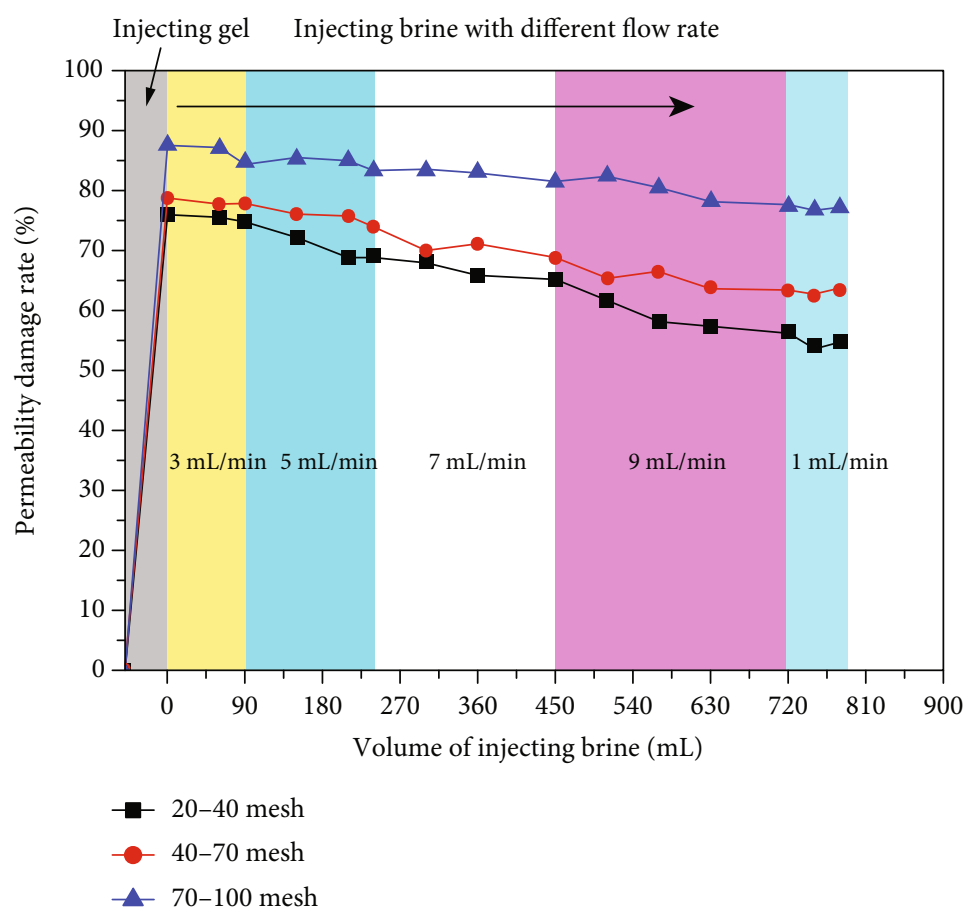

FIGURE 5: Influence of proppant particle size on damage rate of coal sample permeability.

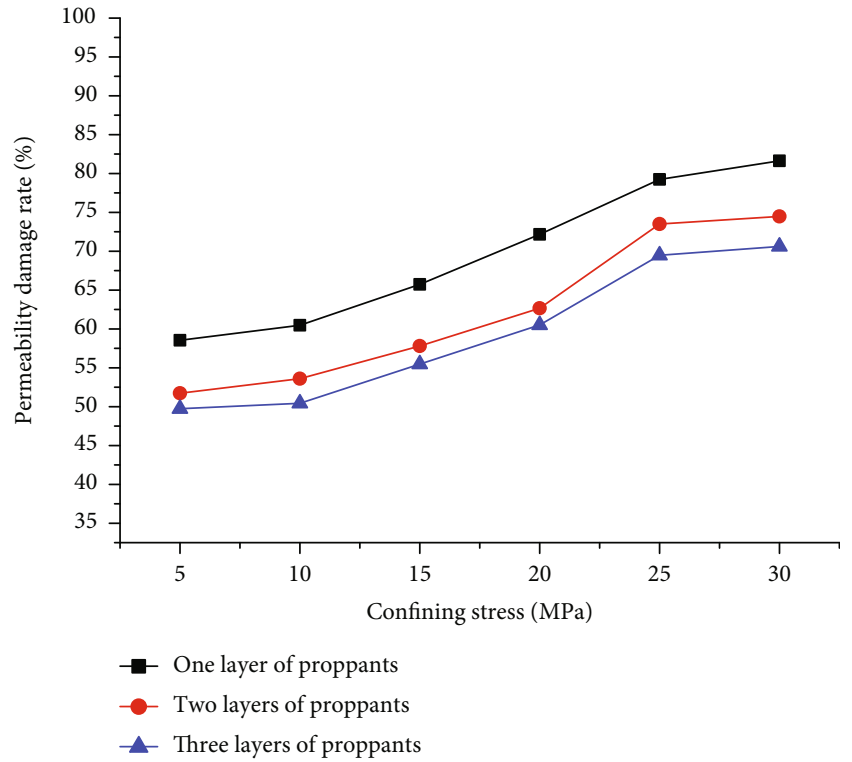

(a)

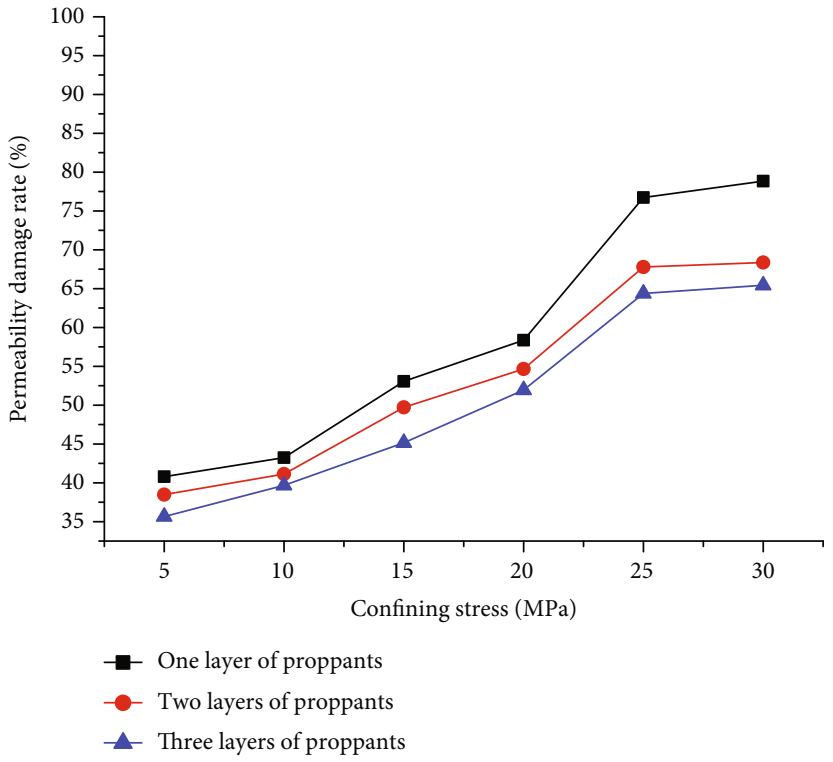

(b)

Figure 6: Influence of various proppant layers on permeability damage rate. (a) Permeability damage rate before brine flushing. (b) Permeability damage rate after brine flushing.

permeability damage experiment is performed according to the experimental steps. The effect of proppant concentration on permeability damage rate was tested under different confining pressures, and the permeability curve is obtained, as shown in Figure 6.

The curve in Figure 6 indicates that there is a considerable difference in the permeability damage rate of coal samples with various proppant concentration. Whether before or after brine flushing, the coal sample permeability damage rate of laying one layer of proppant is greater than that of multilayer laying. As can be seen from Figure 6(a), when the proppant is laid in two and three layers, the effect of confining pressure in the range of $5-10 \mathrm{MPa}$ on coal sample permeability is small. When the confining pressure is in the range of $10-25 \mathrm{MPa}$, the permeability damage rates of laying one layer, laying two layers, and laying three layers all 
TABLE 2: The evaluation indexes of fracturing fluid damage degree.

\begin{tabular}{lccccc}
\hline Damage rate, $\%$ & $<5$ & $<30$ & $30-50$ & $50-70$ & $>70$ \\
\hline The damage degree & None & Weak damage & Moderately weak & Moderately strong & Strong damage \\
\hline
\end{tabular}

increase as the confining pressure increases. The permeability damage rate has a positive correlation with confining pressure. When the confining pressure is in the range of 25-30 MPa, the confining pressure has little effect on the permeability damage rate, and the trend of the permeability damage rate tends to be gentle. The change curve of the permeability damage rate in the three stages is related to the compaction and embedment effects of the proppant. With the low confining pressure, the compaction and embedment effects are not obvious. With the increase of the confining pressure, the compaction and embedment of the proppant reduce the porosity of the pack, thereby increasing the permeability damage rate.

According to Figure 6(b), under the condition of low confining pressure, brine flushing can improve the coal samples permeability with different proppant concentrations and significantly reduce the permeability damage rate. With the increase of confining pressure, the effect of brine flushing on improving the permeability of coal samples becomes smaller. The permeability damage of fracturing fluid to coal samples fracture permeability in proppant single-layer laying is significantly higher than in multilayer. When the proppant is laid in two layers and three layers, the permeability damage rate changes similarly, and there is no obvious difference. The results showed that the permeability of the proppant in the two layers is similar to that in the three layers. Studies have demonstrated that the decrease of channel curvature may be the dominant mechanism for the permeability comparison results between a single-layer and multilayer proppant pack fracture [34].

\section{Discussion}

4.1. Effect of Solid-Phase Adsorption Damage on Permeability. Fracturing fluid and other fluids entering the formation porous medium will cause the reservoir permeability to decrease. The damage mechanism mainly has three aspects: clay water absorption damage, water lock damage, and solid-phase adsorption damage [35]. This experiment used HPG fracturing fluid to study the solid-phase adsorption damage to the reservoir. Solid-phase damage of water-based fracturing fluid mainly refers to the phenomenon that undissolved macromolecular substances in external fluids are adsorbed and retained in the core pore throat, blocking fluid flow channels and causing the decrease of core permeability. The fracturing fluid will not break completely due to the purity of guar powder, so the residue will remain in the supporting fracture during the fracturing fluid flow back process. The presence of residues reduces the porosity of the proppant pack, and the permeability is closely linked to the porosity. Among the many empirical formulas for predicting the permeability of porous media materials, the most famous is the Kozeny-Carman equation proposed by Kozeny and modified by Carman [36]. The Kozeny-Carman equation expression is presented in Equation. (3) [37]. Table 2 provides the evaluation indexes of fracturing fluid damage degree.

$$
K=\frac{\varphi^{3}}{C(1-\varphi)^{2} S^{2}}
$$

where $K$ is the permeability of the porous medium, $10^{-3} \mu \mathrm{m}^{2}$; $\varphi$ is porosity, dimensionless; $C$ is K-C constant, dimensionless; and $S$ is specific surface area, dimensionless.

The fracturing fluid of different concentrations are chosen to characterize the residue damage to the proppant pack. Figure 7 shows the residual of different concentrations of HPG fracturing fluids in the ceramic proppant pack. As can be observed in the figure, when the fracturing fluid concentration is $0.1 \%$, only a few residues exist on the surface of the ceramic proppant. After brine flushing, the residue has little effect on the porosity of the proppant pack, so the permeability damage rate is low. With the concentration of fracturing fluid increased, the residue in the proppant pack increased significantly. While adsorbing on the proppant surface, it blocked the pores of proppant, causing serious damage to the fracture. When the concentration of the fracturing fluid is $0.4 \%$, the guar gel residue is cemented with the ceramic proppant, and the flow channel is severely blocked. The proppant pack porosity is significantly reduced. Although flushing with brine, the damage rate is still high. It can be known from the K-C equation that the reservoir permeability is seriously damaged. When the fracturing fluid concentration is high, there are more residuals, the recovery effect of brine flushing on permeability is limited, and the damage of fracturing fluid residuals on permeability is irreversible. Therefore, reservoir conditions should be fully considered when high-concentration fracturing fluid is used during hydraulic fracturing, to avoid serious damage to the coal reservoir and reduce the fracturing effect [38]. Further studies will be conducted to reduce retention damage of HPG in the ceramic proppant pack. The fracturing fluid should be easy to break the glue thoroughly and have strong sand-carrying capacity, which can increase the fracturing scale and cause less damage to the formation.

4.2. Effect of Formation Water Flushing on Permeability Recovery. In the later stage of hydraulic fracturing, the breaker breaks down the HPG fracturing fluid into a low viscosity fluid and returns to the ground. Proppant is laid in the fracture generated by the fracturing. During the flow back stage of fracturing fluid, macromolecular substances in fracturing fluid (mainly including large particles of fluid, filaments, and floccules) can damage the reservoir mainly in two ways [25]. One way is by directly blocking the fluid flow channel. The other way is that due to the irregular surface of the fracture, when the fluid passes through the fracture, part 


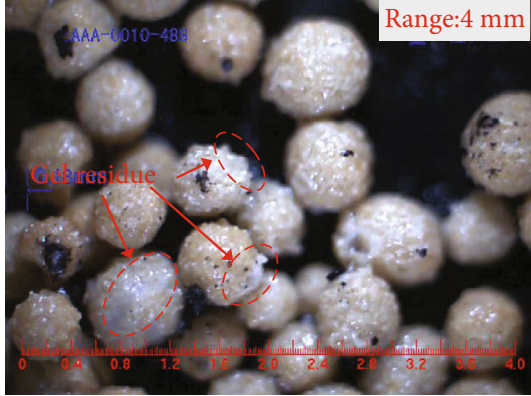

(a)

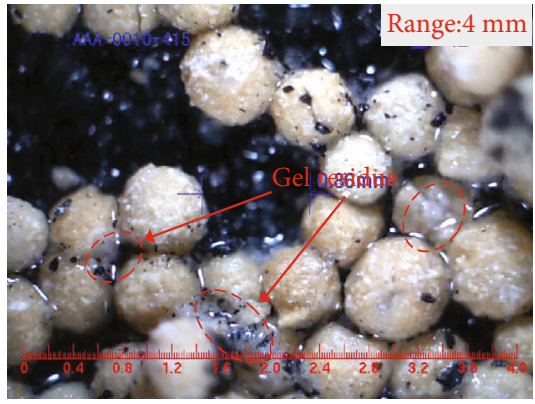

(c)

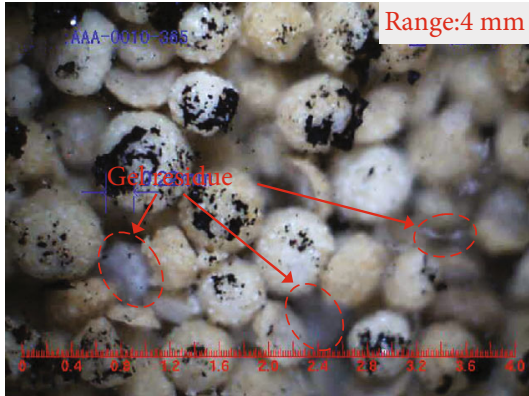

(b)

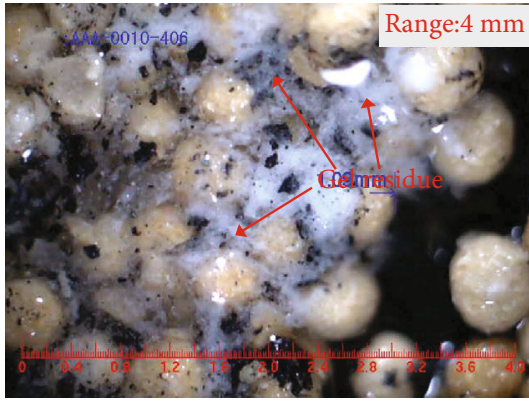

(d)

FIGURE 7: Residues of HPG fracturing fluid with different concentrations in ceramic proppant pack. (a) $0.1 \%$ HPG. (b) $0.2 \%$ HPG. (c) $0.3 \%$ HPG. (d) $0.4 \%$ HPG.

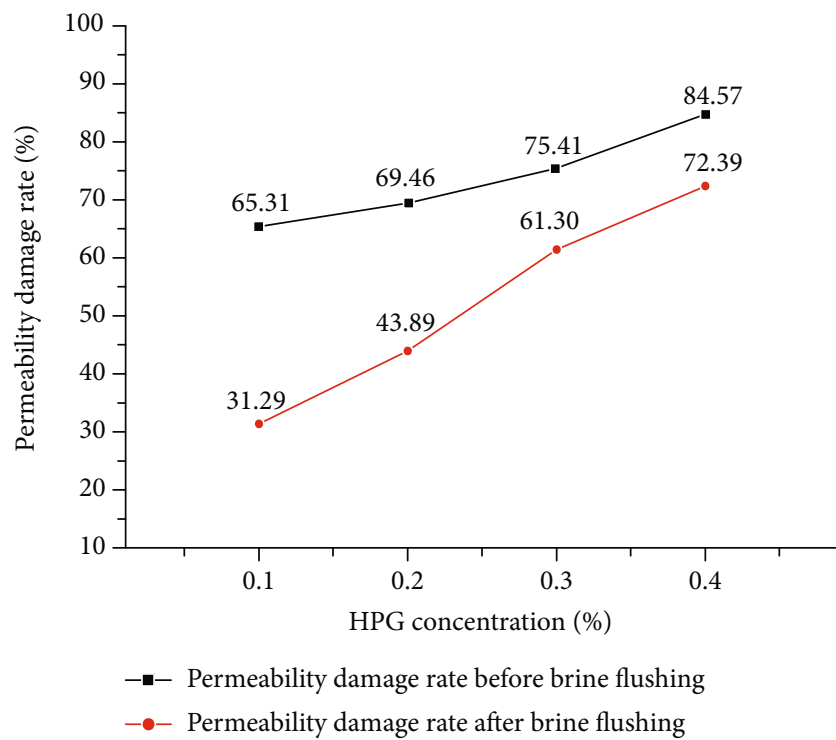

FIGURE 8: Permeability changes before and after brine flushing at different fracturing fluid concentrations.

of the trapped solid-phase material will cause blockage. To make the fracturing fluid fully pass through the coal sample fracture, this paper uses HPG fracturing fluid after gel breaking for experimental simulation.

In Figure 5, the injected KCL brine flow rates were set to $3 \mathrm{~mL} / \mathrm{min}, 5 \mathrm{~mL} / \mathrm{min}, 7 \mathrm{~mL} / \mathrm{min}, 9 \mathrm{~mL} / \mathrm{min}$, and $1 \mathrm{~mL} / \mathrm{min}$, respectively. The flushing time of each flow rate was set to $30 \mathrm{~min}$. We can find that with the injection of brine at different flow rates, the permeability recovers, the damage rate begins to decline, and the permeability eventually stabilizes.
When the flow rates were $3 \mathrm{~mL} / \mathrm{min}$ and $5 \mathrm{~mL} / \mathrm{min}$, the permeability recovery was slower, and $240 \mathrm{~mL}$ of brine was injected at this stage. Subsequently, the brine flushing flow rate was increased to $9 \mathrm{~mL} / \mathrm{min}$, and the damage rate gradually decreased, but the decline rate did not change significantly with the increase of the flow rate. A total of $480 \mathrm{~mL}$ of brine was injected at this flow rate. The permeability remained stable when the injection flow rate changed to $1 \mathrm{~mL} / \mathrm{min}$. The experimental curve shows that there is no linear relationship between the injection flow rate of brine and the recovery of permeability, and the injection volume of brine determines the recovery of permeability. Brine injection volume plays a greater role in permeability recovery than the flushing flow rate. A high flow rate can inject a sufficient amount of brine in a short period time, which requires a sufficiently large displacement during the fracturing process.

As can be observed in Figure 8, the permeability damage rate is approximately linear with the concentration of fracturing fluid before brine flushing. Because the viscosity of HPG solution after breaking is changing with time, the viscosity of HPG solution after breaking is different with different concentrations [39]. To study the effects of fracturing fluid concentration and viscosity on permeability damage rate, we measured the viscosity of fracturing fluid with different concentrations before and after breaking. The viscosity change curve is shown in Figure 9. From the figure, we can find the HPG solutions' final viscosity of four concentrations after the addition of the breaker was reduced to below $10 \mathrm{mPa}$-s. The higher the concentration of fracturing fluid, the longer the time required to break the gel. When the concentration of the HPG solution is $0.1 \%$, the viscosity decreases from $45 \mathrm{mPa}$-s to $3 \mathrm{mPa}$-s after $150 \mathrm{~min}$ of adding 


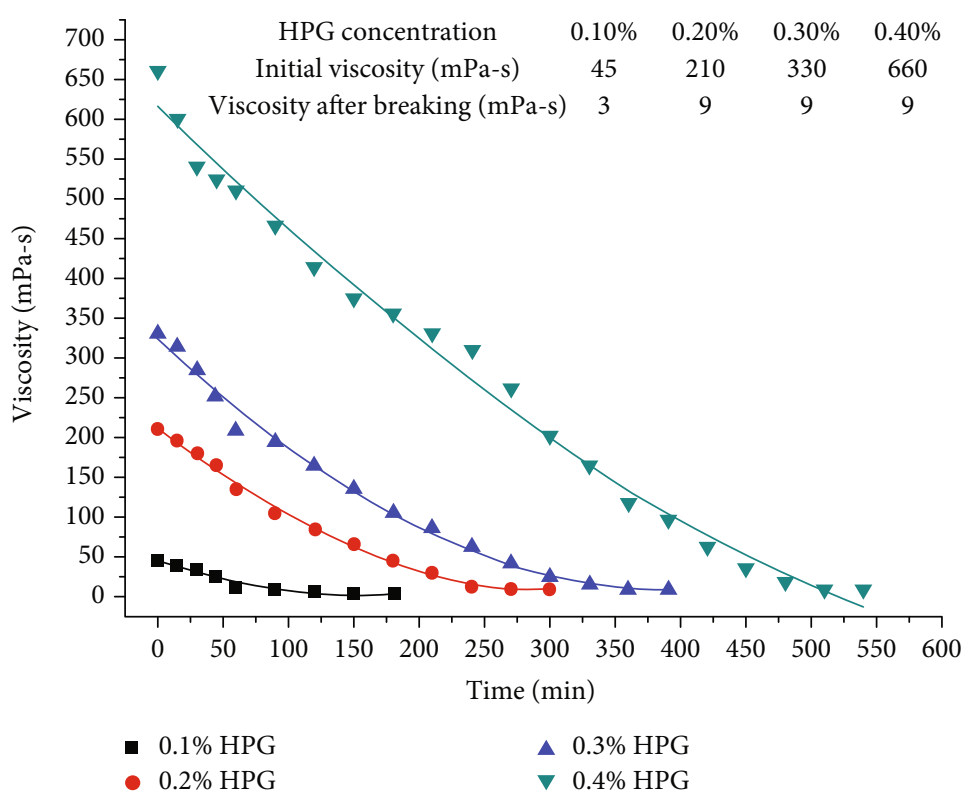

Figure 9: Viscosity changes of four HPG solutions with different concentrations after breaking.

the breaker. After adding a breaker, the concentration of $0.4 \%$ HPG solution required the longest time to reduce the viscosity from $660 \mathrm{mPa}-\mathrm{s}$ to $9 \mathrm{mPa}-\mathrm{s}$, which took about $500 \mathrm{~min}$. The high concentration of fracturing fluid has greater damage to the permeability of coal samples. The main reason is that the higher the concentration of fracturing fluid, the longer it takes to break the gel, which affects the flushing effect of brine. In the process of fracturing fluid flow back, the flushing effect of formation water is closely related to the viscosity of fracturing fluid after breaking. The higher the concentration of the fracturing fluid, the more viscous it is and the longer the break time is required, resulting in more residue in the proppant pack and a higher permeability damage rate.

4.3. Damage to Fracture Permeability by Proppant Embedment and Pulverized Coal. The purpose of hydraulic fracturing is to maximize the flow channel between wellbore, fracture, and reservoir on the premise of minimizing reservoir damage [40]. Since the width of hydraulic fracture is inversely proportional to Young's modulus, the lower Young's modulus is, the wider the fracture will be. Coal have characteristics of low strength, low Young's modulus, and high Poisson's ratio. The fracture generated by hydraulic fracturing of CBM is wide and the fracture length is short [41]. Under the current fracturing conditions, it is difficult to increase the fracture length. It must maintain the fracture width to improve the fracturing effect. Proppant is used to support fractures produced by hydraulic fracturing to provide a flow channel for the desorption of CBM. As the strength of proppant is higher than that of coal, the coal samples are fragile. Proppant embedment and pulverized coal will be occur under high confining pressure. The embedment of the proppant reduces the opening of the fracture. The generated pulverized coal is easily accumulated in the pores of the proppant during the fracturing fluid flow back. Both of

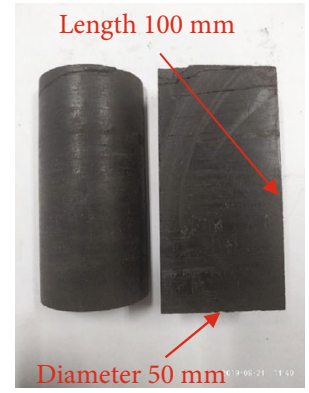

(a)

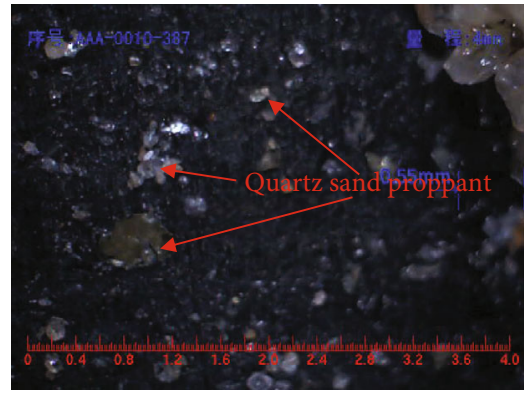

(c)

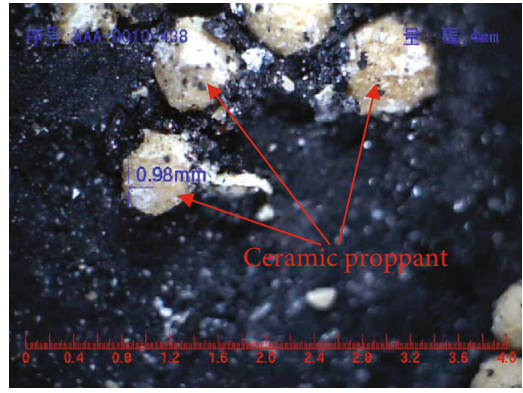

(b)

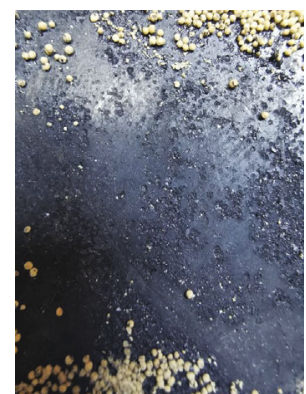

(d)
FIGURE 10: Photograph of the proppant embedment phenomenon. (a) The surface of the coal sample before the experiment. (b) The embedment of the ceramic proppant. (c) The embedment of the quartz sand proppant. (d) The embedment of the coal sample surface after the experiment.

these phenomena will seriously damage the fracture permeability. Figure 10 is a photograph of the coal sample surface before and after the experiment. From the figure, we can find that no matter whether ceramic proppant or quartz sand proppant is used, obviously small pits have formed on the surface of the coal sample after the experiment. It illustrates that the proppant embedment phenomenon is serious. 


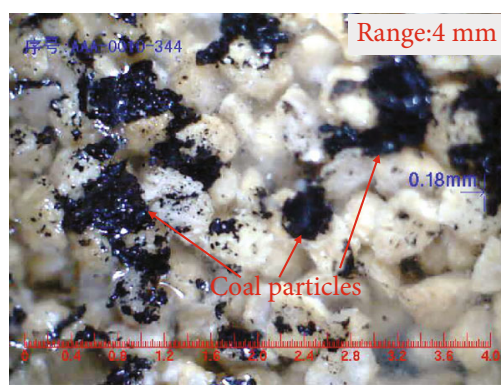

(a)

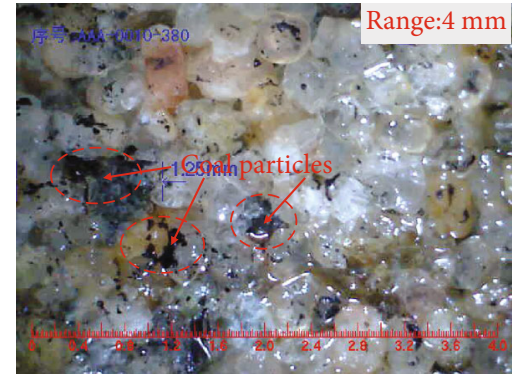

(b)

Figure 11: Distribution of pulverized coal particles in proppant pack. (a) Pulverized coal particles in ceramic proppant. (b) Pulverized coal particles in quartz sand proppant.

In the hydraulic fracturing process, due to the low compressive (tensile) strength of coal, a large amount of pulverized coal is inevitably generated during the initiation and extension of fracture. With the flow back of fracturing fluid, the pulverized coal will accumulate in the fracture. When the pulverized coal content reaches a certain amount, the fracture permeability will be seriously damaged. Figure 11 shows the distribution of pulverized coal particles in the ceramic proppant and quartz sand proppant pack during the experiment. Pulverized coal stays in the pores of the proppant, which exacerbates the decrease in the porosity of the proppant pack and seriously damages the reservoir permeability [42]. During the fracturing process, the fracturing displacement should be fully combined with the mechanical parameters of the reservoir, and appropriate fracturing operation parameters should be selected to reduce the generation of pulverized coal and reduce the damage to the coal reservoir.

\section{Conclusions}

Through a series of flow experiments, the damage of guarbased fracturing fluid to coal sample fracture permeability during the flow back process was studied. The fracture fluid concentration, proppant type, proppant particle size, and proppant concentration were selected as the experimental variables, and the variation law of coal sample permeability damage rate under different experimental variables was obtained. Based on the experimental studies, the following conclusions can be drawn:

(1) The high concentration of fracturing fluid has a higher viscosity. HPG fracturing fluid causes reservoir permeability damage, which is caused by the decrease in porosity of the proppant pack caused by its solid-phase macromolecular substance adsorption and retention. With the increase of fracturing fluid concentration, the permeability damage rate increased from $65.31 \%$ to $84.57 \%$, and the damage degree to permeability was strong. The fracturing fluid concentration is the major factor that fracturing fluid damages the reservoir permeability

(2) Whether before or after KCL brine flushing, the support effect of ceramic proppant is better than quartz sand proppant with different particle sizes. After the brine flushing, the permeability of the ceramic proppant group recovered significantly, but the permeability of the quartz sand group did not recover well. The permeability damage rate of the ceramic proppant group was significantly lower than that of the quartz sand proppant group

(3) When the proppant is laid in a single layer, the permeability damage is greater than that in multiple layers. On the one hand, the proppant multilayer laying improves the proppant pack porosity and makes the fracture have a higher permeability. On the other hand, the proppant embedment in a single layer is more serious, which results in a higher permeability damage rate. With the increase of the embedment depth, the fracture permeability decreases significantly

(4) The permeability damage caused by the adsorption and retention of HPG fracturing fluid residue is irreversible, and the KCL brine flushing only recovers the fracture permeability within a certain range. The brine injection volume plays a decisive role in the recovery of fracture permeability. The high concentration of guar-based fracturing fluid requires more brine volume and longer flushing time due to a longer gel breaking time. Therefore, avoiding too high concentration of guar-based fracturing fluid during fracturing operation, increasing the flow back time, and having a sufficient amount of the breaker are the key to reservoir protection during CBM fracturing stimulation

\section{Data Availability}

The data used to support the findings of this study are available from the corresponding author upon request.

\section{Conflicts of Interest}

The authors declared that they have no conflicts of interest to this work. 


\section{Acknowledgments}

This research was financially supported by National Nature Science Foundation of China (No. 51274205).

\section{References}

[1] H. Li, H. C. Lau, and S. Huang, "Coalbed methane development in China: engineering challenges and opportunities," in SPE/IATMI Asia Pacific Oil \& Gas Conference and Exhibition, Society of Petroleum Engineers, 2017.

[2] Y. Cheng, X. Wang, and Y. Ding, Theory and application of optimal design for coalbed methane fracturing, China university of petroleum press, Dongying, China, 2018.

[3] Y. Cao and X. Wang, "Economic evaluation of CBM gas development projects," Natural Gas Industry, vol. 31, no. 11, pp. 103-106, 2011.

[4] W. Heo, W. Lee, and D. S. Lee, "Hydraulic fracturing design for coalbed methane in Barito Basin, Indonesia," Geosystem Engineering, vol. 18, no. 3, pp. 151-162, 2015.

[5] T. A. Moore, "Coalbed methane: a review," International Journal of Coal Geology, vol. 101, pp. 36-81, 2012.

[6] Q. Huang, S. Liu, G. Wang, B. Wu, and Y. Zhang, "Coalbed methane reservoir stimulation using guar-based fracturing fluid: A review," Journal of Natural Gas Science and Engineering, vol. 66, pp. 107-125, 2019.

[7] C. M. He, B. Cai, Y. J. Lu, G. F. Duan, and Z. Liu, "Study on microscopic mechanism of sand carrying by guar fracturing fluid," Oilfield Chem, vol. 32, pp. 34-38, 2015.

[8] M. P. Kreipl and A. T. Kreipl, "Hydraulic fracturing fluids and their environmental impact: then, today, and tomorrow," Environment and Earth Science, vol. 76, no. 4, 2017.

[9] Q. Huang, S. Liu, G. Wang, B. Wu, Y. Yang, and Y. Liu, "Gas sorption and diffusion damages by guar-based fracturing fluid for CBM reservoirs," Fuel, vol. 251, pp. 30-44, 2019.

[10] X. Li and Y. Kang, "Effect of fracturing fluid immersion on methane adsorption/desorption of coal," Journal of Natural Gas Science and Engineering, vol. 34, pp. 449-457, 2016.

[11] J. Wen, W. Cheng, L. Chen, S. Shi, and Z. Wen, "A study of the dynamic movement rule of overlying strata combinations using a short-wall continuous mining and full-caving method," Energy Science \& Engineering, vol. 7, no. 6, pp. 2984-3004, 2019.

[12] Y. Lu, F. Yang, Z. Ge, Q. Wang, and S. Wang, "Influence of viscoelastic surfactant fracturing fluid on permeability of coal seams," Fuel, vol. 194, pp. 1-6, 2017.

[13] Z. Wen, S. Jing, Y. Jiang et al., "Study of the Fracture Law of Overlying Strata under Water Based on the Flow- StressDamage Model," Geofluids, vol. 2019, Article ID 3161852, 12 pages, 2019.

[14] S. R. Xie, B. Yang, Q. Zhang, H. Z. Song, H. X. Suo, and T. Zhang, "Research on lift pressure system with combined pipeline and intensive drill-hole gas drainage along the layer in low permeability coal seam," Journal of Mining Sciences, vol. 4, no. 1, pp. 34-40, 2019.

[15] R. Puri, G. E. King, and I. D. Palmer, "Damage to coal permeability during hydraulic fracturing," in Low permeability reservoirs symposium, Society of Petroleum Engineers, 1991.

[16] M. A. A. Ahamed, M. S. A. Perera, L. Dong-yin, P. G. Ranjith, and S. K. Matthai, "Proppant damage mechanisms in coal seam reservoirs during the hydraulic fracturing process: A review," Fuel, vol. 253, pp. 615-629, 2019.

[17] Y. Kang, F. Huang, L. You, X. Li, and B. Gao, "Impact of fracturing fluid on multi-scale mass transport in coalbed methane reservoirs," International Journal of Coal Geology, vol. 154155, pp. 123-135, 2016.

[18] Y. Y. Lu, F. Yang, Z. L. Ge, Z. Zhou, and X. D. Lin, “Comparative experiment on influence of clear fracturing fluid and water on coal seam permeability," Journal of China Coal Society, vol. 40, no. 1, pp. 93-97, 2015.

[19] J. Guo and C. He, "Microscopic mechanism of the damage caused by gelout process of fracturing fluids," Acta Petrolei Sinica, vol. 33, no. 6, pp. 1018-1022, 2012.

[20] Y. Kang, D. Chen, and X. Li, "Effect of fracturing fluid treatment on pore structure of coal," Journal of China University of Petroleum, vol. 38, no. 5, pp. 102-108, 2014.

[21] X. C. Li, L. Zhang, J. F. Zhao, L. Xie, Z. B. Li, and Y. Song, "Coal deformation characteristics in gas adsorption and desorption," Journal of Mining Sciences, vol. 3, no. 1, pp. 46-54, 2018.

[22] S. Liu and S. Harpalani, "Permeability prediction of coalbed methane reservoirs during primary depletion," International Journal of Coal Geology, vol. 113, pp. 1-10, 2013.

[23] R. Barati and J. T. Liang, "A review of fracturing fluid systems used for hydraulic fracturing of oil and gas wells," Journal of Applied Polymer Science, vol. 131, pp. 1-11, 2014.

[24] J. Zhang, L. Ouyang, D. Zhu, and A. D. Hill, "Experimental and numerical studies of reduced fracture conductivity due to proppant embedment in the shale reservoir," Journal of Petroleum Science and Engineering, vol. 130, pp. 37-45, 2015.

[25] L. Z. Cong, J. F. Chen, Z. P. Li, and S. A. Zhang, "Adsorption features of fracturing fluid by coal substrate during the fracturing process in coal bed methane well," Meitian Dizhi yu Kantan(Coal Geology \& Exploration), vol. 35, pp. 27-30, 2007.

[26] B. Jia, J. S. Tsau, and R. Barati, "A review of the current progress of $\mathrm{CO} 2$ injection EOR and carbon storage in shale oil reservoirs," Fuel, vol. 236, pp. 404-427, 2019.

[27] W. Huang, M. Lei, Z. Qiu, Y. K. Leong, H. Zhong, and S. Zhang, "Damage mechanism and protection measures of a coalbed methane reservoir in the Zhengzhuang block," Journal of Natural Gas Science and Engineering, vol. 26, pp. 683-694, 2015.

[28] J. C. Pashin, "Hydrodynamics of coalbed methane reservoirs in the Black Warrior Basin: key to understanding reservoir performance and environmental issues," Applied Geochemistry, vol. 22, no. 10, pp. 2257-2272, 2007.

[29] H. Z. Zhang, L. P. Wang, and J. Liu, "The status and development trend of coalbed methane development technology," Oil Forum, vol. 32, pp. 17-21, 2013.

[30] S. P. Wang, X. Z. Zhao, B. Cai, and S. Hua, "Study of new ultratemperature polymer fracturing fluid material," Advances in Materials Research, vol. 1061-1062, pp. 283-286, 2015.

[31] B. Jia, L. Jin, B. A. F. Mibeck, S. A. Smith, and J. A. Sorensen, "An integrated approach of measuring permeability of naturally fractured shale," Journal of Petroleum Science and Engineering, vol. 186, p. 106716, 2019.

[32] H. Darcy, "Determination of the laws of flow of water through sand," Physical hydrology, 1983.

[33] S. Zhou, Study on retention of hydroxypropyl guar gum to porous media consist of ceramsite, Southwest Petroleum University, 2018. 
[34] Y. Wu, Z. Pan, D. Zhang, D. I. Down, Z. Lu, and L. D. Connell, "Experimental study of permeability behaviour for proppant supported coal fracture," Journal of Natural Gas Science and Engineering, vol. 51, pp. 18-26, 2018.

[35] Y. Cao, Z. Qu, and T. Guo, "Experimental study on damage mechanism of water-based fracturing fluid to reservoir," Journal of Xi'an Shiyou University (Natural Science Edition), vol. 31, no. 2, pp. 87-92, 2016.

[36] G. Mavko and A. Nur, "The effect of a percolation threshold in the Kozeny-Carman relation," Geophysics, vol. 62, no. 5, pp. 1480-1482, 1997.

[37] R. L. Kleinberg, C. Flaum, D. D. Griffin et al., "Deep sea NMR: methane hydrate growth habit in porous media and its relationship to hydraulic permeability, deposit accumulation, and submarine slope stability," Journal of Geophysical Research: Solid Earth, vol. 108, no. B10, pp. 2508-2522, 2003.

[38] A. Reinicke, E. Rybacki, S. Stanchits, E. Huenges, and G. Dresen, "Hydraulic fracturing stimulation techniques and formation damage mechanisms-Implications from laboratory testing of tight sandstone-proppant systems," Chemie der Erde-Geochemistry, vol. 70, pp. 107-117, 2010.

[39] S. Wang, Y. Zhang, J. Guo et al., "A study of relation between suspension behavior and microstructure and viscoelastic property of guar gum fracturing fluid," Journal of Petroleum Science and Engineering, vol. 124, pp. 432-435, 2014.

[40] Z. Chen, R. G. Jeffrey, and X. Zhang, "Numerical modeling of three-dimensional T-shaped hydraulic fractures in coal seams using a cohesive zone finite element model," Hydraulic Fracturing Journal, vol. 2, no. 2, pp. 20-37, 2015.

[41] X. Zhang, P. Zhang, H. Liu, and S. Miao, "Fracture extended model under hydraulic fracturing engineering for high rank coal reservoirs," Journal of China University of Mining \& Technology, vol. 42, no. 4, pp. 573-579, 2013.

[42] L. B. Neto, A. Khanna, and A. Kotousov, "Conductivity and performance of hydraulic fractures partially filled with compressible proppant packs," International Journal of Rock Mechanics and Mining Sciences, vol. 74, pp. 1-9, 2015. 